\title{
A double blind placebo controlled group comparative study of ophthalmic sodium cromoglycate and nedocromil sodium in the treatment of vernal keratoconjunctivitis
}

\author{
Medhat El Hennawi
}

\begin{abstract}
In a 4 week double masked comparative study, patients received $2 \%$ nedocromil sodium (48), $2 \%$ sodium cromoglycate (48), or placebo eye drops (42), four times daily, for the treatment of vernal keratoconjunctivitis (VKC). Clinical examinations of eye condition and symptom severity were made before and after a 1 week baseline before starting test treatment, and after 1,2 , and 4 weeks of treatment. Patients kept daily diary card records of symptom. severity and concomitant therapy. At the clinic, significant improvements were seen with both active treatments after 2-4 weeks. During the final visit, significant benefits over placebo were recorded for five ocular signs with nedocromil sodium and three with sodium cromoglycate, bulbar and lower tarsal chemosis being better controlled by nedocromil sodium ( $\mathbf{p}<0.05 v$ sodium cromoglycate). Diary card trends showed improvement with all three treatments, which was greatest with nedocromil sodium and least with placebo. Compared with placebo, both the active drugs produced statistically significant improvements in general eye condition during weeks 1-2, and nedocromil sodium significantly reduced itching within the first week. Overall, nedocromil sodium had the greatest effect on symptoms, although diary card data revealed no statistically significant differences between the two active drugs. In conclusion, both $2 \%$ nedocromil sodium and $2 \%$ sodium cromoglycate were effective in controlling VKC when administered four times daily into the eyes, while the marked anti-inflammatory activity of nedocromil sodium was apparent in its more pronounced overall therapeutic effect.

(Br F Ophthalmol 1994; 78: 365-369)
\end{abstract}

Vernal keratoconjunctivitis (VKC) is a noninfectious allergic condition which predominantly affects male children and young adults and occurs most commonly in warmer climates. Symptoms are often associated with the presence of grass pollen and are worst during the spring and early summer in atopic patients who manifest 'vernal catarrah'. However, severely affected patients exhibit symptoms throughout the year, with exacerbations occurring during the pollen season. VKC can be distinguished from other forms of conjunctivitis by the presence of giant 'cobblestone' papillae on the upper tarsal conjunctiva and/or hypertrophy of the limbal conjunctiva, often accompanied by hyperaemia, oedema, and localised chalky accumulations of eosinophils, known as Trantas' dots. ${ }^{2}$ Typical clinical symptoms include intense itching, photophobia, increased lacrimation, and production of thick, stringy mucus. The disease involves the infiltration of inflammatory cells including mast cells, lymphocytes, eosinophils, and basophils. ${ }^{3}$ Eosinophils and mast cells, notably those of the mucosal $\left(\mathrm{MC}_{\mathrm{T}}\right)$ type, increase and invade the conjunctival epithelium. ${ }^{4}$ Lymphocytes invading the conjunctiva in VKC were recently shown to be interleukin 4 producing helper $T$ cells, promoting IgE antibody synthesis and the activation of mast cells, basophils, and eosinophils. ${ }^{5}$ Inflammatory and cytotoxic mediators released from these invading cells are implicated in the clinical symptoms and signs of VKC which, when severe, can include corneal pannus formation, punctate epithelial keratopathy and vision damaging corneal ulceration.

Therapies available for VKC include corticosteroids, sodium cromoglycate, and vasoconstrictors, with or without antihistamines. ${ }^{6}$ Owing to their anti-inflammatory action, topical corticosteroids are useful in controlling severe symptoms but long term use is associated with the risk of glaucoma, cataract formation, potentiation of infection, and other potentially hazardous and sight threatening side effects. ${ }^{7}$ Sodium cromoglycate, a non-toxic mast cell stabiliser with in vitro cellular anti-inflammatory activity ${ }^{89}$ has proved effective in the treatment of VKC ${ }^{10}$ and other ocular allergic conditions. ${ }^{.1}$

Nedocromil sodium is a recently developed topically effective drug which has similar, nontoxic, pharmacological properties to sodium cromoglycate but shows increased potency both in clinical tests and in the laboratory.12 Nedocromil sodium is the more efficient inhibitor of activated inflammatory cells such as eosinophils $s^{13}$ and, unlike sodium cromoglycate, which appears to stabilise only connective tissue type mast cells $\left(\mathrm{MC}_{\mathrm{TC}}\right)$, nedocromil sodium will also stabilise mucosal mast cells $\left(M C_{T}\right) \cdot{ }^{14}$ Since the proportion of $M C_{T}$ type conjunctival mast cells is increased in VKC, ${ }^{4}$ nedocromil sodium should be a more effective treatment than sodium cromoglycate. A placebo controlled study carried out in Italy showed that nedocromil sodium $2 \%$ eye drops (Tilavist, Fisons plc), used four times daily over a 6 week period, significantly improved symptoms of 
VKC and at the same time reduced inflammatory cells present in the tears. ${ }^{1516}$ This is the first fully reported study comparing $2 \%$ ophthalmic nedocromil sodium with $2 \%$ ophthalmic sodium cromoglycate (Opticrom, Fisons plc) and placebo in the treatment of VKC.

\section{Materials and methods}

\section{STUDY DESIGN}

At admission, which was followed by a 1 week baseline, patients were assessed for eligibility based on clinical signs and symptoms and a medical history of bilateral VKC. They were then assigned, according to a randomisation code provided with the test materials, to receive either $2 \%$ sodium cromoglycate, $2 \%$ nedocromil sodium, or placebo eye drops for 4 weeks, one drop into each eye four times daily. The patients were supplied with daily diary cards on which they recorded symptom severity and use of concomitant medication. Clinic visits were made after 1, 2, and 4 weeks of treatment, when clinical assessments of symptom severity and examinations of the conjunctiva and cornea were performed.

The study was carried out in accordance with the principles of the revised Declaration of Helsinki (Venice, 1983) and all patients or parents gave their written informed consent.

\section{PATIENT POPULATION}

A total of 138 patients with a diagnosis of VKC, $70 \%$ of whom were male, took part in the study. Ages ranges from 3 to 36 years (mean 13.5 years) and the duration of the disease ranged from first attack to 30 years, with a mean of $4 \cdot 3$ years. Characteristics were evenly spread among the treatment groups. Eight patients (four in the nedocromil sodium group and two in each of the other groups) had a history of atopic disease (allergic dermatitis) and four (three nedocromil sodium, one sodium cromoglycate) had a family history of atopic disease. Excluded were contact lens wearers and patients with infective, grossly purulent conjunctivitis, or ophthalmic pathology other than that related to the external eye. Individuals known to be sensitive to the eye drop components benzalkonium chloride, disodium edetate, or riboflavin were also excluded. Systemic corticosteroids and ophthalmic sodium cromoglycate were not to have been used for at least 2 weeks before trial entry.

\section{MEDICATION}

The test treatments ( $2 \%$ nedocromil sodium, $2 \%$ sodium cromoglycate, and placebo) were supplied as aqueous solutions in similar metered dose packs containing $0.01 \%$ benzalkonium chloride and $0.05 \%$ disodium edetate as preservative. Sodium cromoglycate and placebo eye drops contained riboflavin as a yellow colorant. The study protocol permitted use of a predetermined dose of topical corticosteroid if considered by the clinician to be absolutely necessary to control symptoms; otherwise no ophthalmic treatment was permitted.
EFFICACY VARIABLES

Patients were issued with diary cards on which they recorded general eye condition and severity of itching, soreness, grittiness, watery discharge, sticky discharge, redness, and photophobia, on a 5 point scale $(0=$ none, $1=$ mild, $2=$ moderate, $3=$ severe, $4=$ very severe). Daily usage of test medication and any additional treatment were also recorded. Clinical assessments of itching, soreness, grittiness, photophobia, blepharospasm, watery discharge, sticky discharge, and ptosis (right and left eye separately in each case) were made at the end of baseline and after 1, 2, and 4 weeks of treatment. Examinations of the conjunctiva for signs of hyperaemia, chemosis, papillae, follicles, and scarring of the bulbus and upper and lower tarsi; and of the cornea/limbus for Trantas' dots, filaments, mucoid plaques, oedema, nodules, pannus, ulceration, punctate epithelial keratitis, and opacities were also carried out. Clinical signs and symptoms were recorded by the same 5 point scale as used on the diary cards. At the end of the trial patients and clinician gave their overall opinions of the treatment, from 'no response' ( 0$)$ to 'full control of symptoms' (3).

\section{SAFETY VARIABLES}

Any adverse or unusual symptoms were noted by the patient on the diary card and at each visit the investigator discussed any event which might have indicated an adverse drug reaction, recording relevant information on the clinic assessment form.

\section{STATISTICAL ANALYSIS}

Non-parametric methods were used. Treatment groups were compared for each variable, including final opinions, using a Kruskal-Wallis test. Weekly diary card scores were compared as changes from baseline, as were clinical assessments of signs and symptoms (using the mean score for both eyes) after 1, 2, and 4 weeks of treatment. Where a significant treatment effect was seen, pairwise comparisons were carried out using Mann-Whitney U tests. All tests were two tailed, at the $5 \%$ level of significance.

\section{Results}

From an original patient entry of 150,12 failed to return to the clinic after the baseline period and were excluded from the analysis. None of the remaining patients withdrew from the study and data from all 138 subjects were analysed for efficacy and safety, grouped as 48 sodium cromoglycate, 48 nedocromil sodium, and 42 placebo treatments. Compliance with the study protocol was generally very good. Two patients (one sodium cromoglycate, one placebo) used vasoconstrictors during the first week of test treatment, but topical corticosteroids were not used at all.

Diary card scores showed an improvement in all symptoms with all three treatments over the 4 weeks of the trial. Scores for general eye condition are summarised in Table 1 , and those for itching in Figure 1. Improvements were 
Table 1 Diary card severity scores for general eye condition: significance of changes from baseline during 4 weeks of trial treatment (symptom severity scores: $0=$ none; $1=$ mild; $2=$ moderate; $3=$ severe; $4=$ very severe)

\begin{tabular}{|c|c|c|c|c|c|}
\hline \multirow[b]{2}{*}{ Treatment group } & \multirow{2}{*}{$\begin{array}{l}\text { Baseline } \\
\text { (mean score) }\end{array}$} & \multicolumn{4}{|c|}{ Mean change from baseline } \\
\hline & & Week 1 & Week 2 & Week 3 & Week 4 \\
\hline $\begin{array}{l}\text { Nedocromil sodium } \\
\text { Sodium cromoglycate } \\
\text { Placebo }\end{array}$ & $\begin{array}{l}3 \cdot 40 \\
3 \cdot 42 \\
3 \cdot 18\end{array}$ & $\begin{array}{l}-1.12 \\
-0.95 \\
-0.57\end{array}$ & $\begin{array}{l}-1 \cdot 60 \\
-1 \cdot 38 \\
-1 \cdot 09\end{array}$ & $\begin{array}{l}-1 \cdot 67 \\
-1.43 \\
-1 \cdot 23\end{array}$ & $\begin{array}{l}-1.91 \\
-1.67 \\
-1.43\end{array}$ \\
\hline $\begin{array}{l}\text { Statistical significance of treatment difference } \\
\text { (Kruskal-Wallis test) }\end{array}$ & $p=0.112$ & $\mathrm{p}=0.003^{\star \star}$ & $\mathrm{p}=0.026^{\star}$ & $p=0.090$ & $\mathrm{p}=0.054$ \\
\hline $\begin{array}{l}\text { Pairwise comparisons of significant treatment } d \\
\text { (Mann-Whitney test) } \\
\text { Nedocromil sodium } v \text { placebo } \\
\text { Sodium cromoglycate } v \text { placebo } \\
\text { Nedocromil sodium } v \text { sodium cromoglycate }\end{array}$ & & $\begin{array}{l}p=0.0005^{\star \star \star} \\
p=0.030^{\star} \\
p=0.318\end{array}$ & $\begin{array}{l}p=0.015^{\star} \\
p=0.045^{\star} \\
p=0.267\end{array}$ & & \\
\hline
\end{tabular}

${ }^{\star \star \star} \mathrm{p}<0.001 ;{ }^{\star \star} \mathrm{p}<0.01 ;{ }^{\star} \mathrm{p}<0.05$

generally greatest with nedocromil sodium and were always least with placebo, although the placebo effect itself became considerable by the end of the trial period. Baseline mean symptom scores were similar across the treatment groups and ranged from moderate to severe $(2 \cdot 3-3 \cdot 7)$. By the end of the 4 weeks of treatment, reductions in score of $1 \cdot 0-2 \cdot 2$ had occurred in all three groups, resulting in mild/moderate symptoms only. The two active drugs reduced symptoms more rapidly, however, and during the first 2 weeks of treatment both were significantly better than placebo for general eye condition (nedocromil sodium $\mathrm{p}=\mathbf{0 . 0 0 0 5}, \mathrm{p}=\mathbf{0 . 0 1 5}$; sodium cromoglycate $\mathrm{p}=0.030, \mathrm{p}=0.045$ ). Nedocromil sodium was also significantly better than placebo for itching in the first week $(p=0 \cdot 01)$. After 3-4 weeks, as the placebo effect grew, the continuing improvements in general eye condition with the active therapies fell just short of statistical significance $(p<0 \cdot 10)$. Despite a consistent trend in favour of nedocromil sodium for all the subjective diary card symptoms except soreness, none of the differences between nedocromil sodium and sodium cromoglycate was statistically significant.

Assessments of eye symptoms by the clinician at clinic visits were in agreement with the diary card results; however, no statistically significant differences occurred among the treatment groups.

Clinical signs of the conjunctiva and cornea/ limbus showed improvements with all three

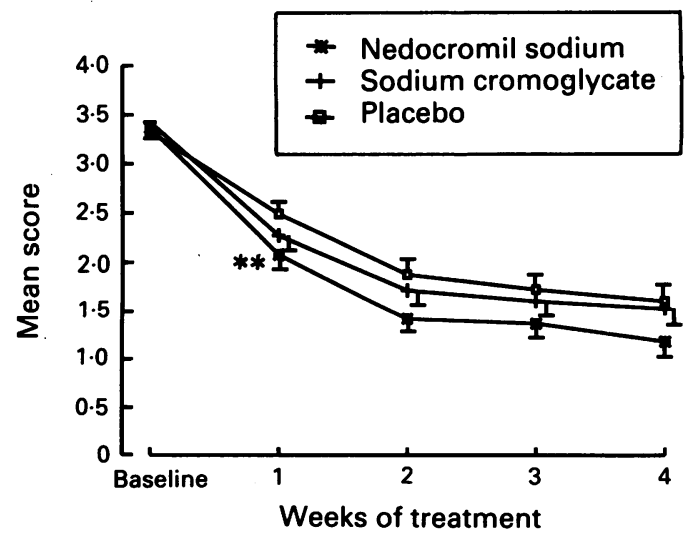

Figure 1 Diary card severity scores for itching during trial treatment. (Score: $4=$ very severe; $3=$ severe; $2=$ moderate; $I=$ mild; $0=$ none.) Significance (pairwise comparison of changes from baseline): ${ }^{\star \star} p=0.010$ nedocromil sodium $\mathrm{v}$ placebo.

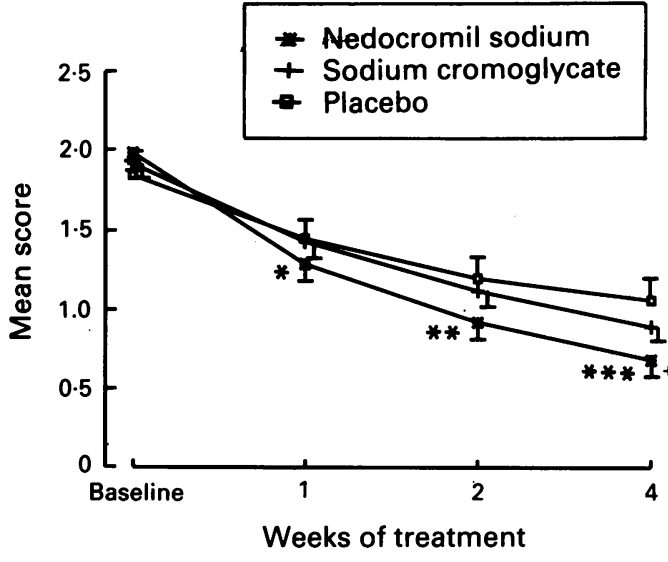

Figure 2 Clinical assessments of bulbar conjunctival chemosis. (Score: $4=$ very severe; $3=$ severe; $2=$ moderate; $1=$ mild; $0=$ none.) Significance (pairwise comparison of changes from baseline): ${ }^{\star \star \star} p=0.001,{ }^{\star \star} p=0.003$, ${ }^{\star} p=0.015$ nedocromil sodium $\mathrm{v}$ placebo, ${ }^{+} p=0.041$ nedocromil sodium $\mathrm{v}$ sodium cromoglycate.

treatments, ranked always in order of efficacy as nedocromil sodium $>$ sodium cromoglycate $>$ placebo, although statistical significance was not commonly achieved. Bulbar and tarsal conjunctival hyperaemia, which was moderately severe (scoring about 2.5) for all groups at baseline, was reduced to the mild/moderate range $(1 \cdot 0-1 \cdot 5)$ after 4 weeks, with no significant treatment differences. Tarsal papillae showed a similar degree of improvement, whereas for bulbar papillae (baseline score 1.9-2.4) both the active drugs gave a significantly $(\mathrm{p}<0.01)$ greater reduction in mean score than placebo after 4 weeks (respectively, $-1 \cdot 22,-1 \cdot 16, v-0.63$ ). This effect was also evident after 2 weeks $(p<0.05)$. The moderate degree of conjunctival chemosis (scores about 2.0) present during the baseline was also reduced significantly, to 0.8 or less, but only by nedocromil sodium $(p=0.015$, $p=0.003, p=0.001, v$ placebo for bulbar chemosis, weeks $1,2,4$, and for lower tarsal chemosis, $p=0.02$, week 4 ).

The effect of sodium cromoglycate on chemosis was similar to placebo, and proved significantly less than that of nedocromil sodium for lower tarsus $(p=0.008, p=0.018)$ weeks $2-4$, and for bulbar conjunctiva $(p=0.041)$ week 4 (Fig 2). Scarring of the conjunctiva, though always very slight, was reduced even further by the trial treatments, and almost totally by nedocromil sodium; treatment differences were not sígnificant. 
Table 2 Clinical assessment of ocular signs of vermal keratoconjunctivitis (VKC) at the end of the 4 week trial treatment period: pairwise comparison of changes in severity score (Mann-Whitney test; only those signs showing significant treatment effects at the final clinic visit are given). (Score: $0=$ none; $1=$ mild; $2=$ moderate; $3=$ severe; $4=$ very severe)

\begin{tabular}{|c|c|c|c|c|c|c|}
\hline \multirow{2}{*}{$\begin{array}{l}\text { Severity scores for signs of VKC in } \\
\text { conjunctiva and corneallimbus }\end{array}$} & \multirow{2}{*}{$\begin{array}{l}\text { Nedocromil } \\
\text { sodium } \\
(N) n=48\end{array}$} & \multirow{2}{*}{$\begin{array}{l}\text { Sodium } \\
\text { cromoglycate } \\
\text { (C) } n=48\end{array}$} & \multirow{2}{*}{$\begin{array}{l}\text { Placebo } \\
(P) n=42\end{array}$} & \multicolumn{3}{|l|}{ p Values } \\
\hline & & & & $N \times P$ & $C \times P$ & $N \times C$ \\
\hline $\begin{array}{l}\text { Lower tarsal chemosis: } \\
\text { Baseline score } \\
\text { Change from baseline }\end{array}$ & $\begin{array}{r}1.90 \\
-1 \cdot 23\end{array}$ & $\begin{array}{r}1 \cdot 76 \\
-0 \cdot 88\end{array}$ & $\begin{array}{r}1 \cdot 88 \\
-0.87\end{array}$ & $0.020^{\star}$ & 0.692 & $0.018^{\star}$ \\
\hline $\begin{array}{l}\text { Bulbar chemosis: } \\
\text { Baseline score } \\
\text { Change from baseline }\end{array}$ & $\begin{array}{r}1.99 \\
-1.31\end{array}$ & $\begin{array}{r}1.92 \\
-1.03\end{array}$ & $\begin{array}{r}1.85 \\
-0.79\end{array}$ & $0.001^{\star \star \star}$ & $0 \cdot 112$ & $0 \cdot 141^{\star}$ \\
\hline $\begin{array}{l}\text { Bulbar papillae: } \\
\text { Baseline score } \\
\text { Change from baseline }\end{array}$ & $\begin{array}{r}2 \cdot 11 \\
-1 \cdot 22\end{array}$ & $\begin{array}{r}2 \cdot 36 \\
-1 \cdot 16\end{array}$ & $\begin{array}{r}1.90 \\
-0.63\end{array}$ & $0.004^{\star \star}$ & $0.008^{\star \star}$ & 0.634 \\
\hline $\begin{array}{l}\text { Trantas' dots: } \\
\text { Baseline score } \\
\text { Change from baseline }\end{array}$ & $\begin{array}{r}1 \cdot 54 \\
-1 \cdot 17\end{array}$ & $\begin{array}{r}1 \cdot 84 \\
-1 \cdot 17\end{array}$ & $\begin{array}{r}1.42 \\
-0.69\end{array}$ & $0.013^{\star}$ & $0 \cdot 014^{\star}$ & 0.930 \\
\hline $\begin{array}{l}\text { Nodules: } \\
\text { Baseline score } \\
\text { Change from baseline }\end{array}$ & $\begin{array}{r}2.05 \\
-1.02\end{array}$ & $\begin{array}{r}2 \cdot 22 \\
-1 \cdot 15\end{array}$ & $\begin{array}{r}1.85 \\
-0.61\end{array}$ & $0.042^{\star}$ & $0.006^{\star \star}$ & 0.530 \\
\hline
\end{tabular}

$\star \star \star p \leqslant 0.001 ;{ }^{\star \star} p<0.01 ;{ }^{\star} p<0.05$

Corneal ulceration, punctate epithelial keratitis and opacities were rarely seen. Most other corneal/limbal signs were mild (baseline score $<1 \cdot 0)$ and following any 4 week treatment filaments, mucoid plaques, and pannus were virtually absent in most of the patients. Even so, the effects of both active treatments were significantly $(\mathrm{p}<0.05)$ better than placebo for oedema at week 2 (Fig 3). Moderate baseline scores for Trantas' dots $(1 \cdot 4-1 \cdot 8)$ and nodules $(1 \cdot 9-2 \cdot 2)$ were significantly $(\mathrm{p}<0.05)$ reduced by both active drugs $v$ placebo, after $2-4$ weeks and 4 weeks, respectively. Pairwise comparisons of clinical assessments at the end of treatment are summarised in Table 2.

Patient opinion showed a preferential trend for nedocromil sodium, followed by sodium cromoglycate: thus, $79 \%$ (38/48) considered nedocromil sodium to give full or moderate control of symptoms, compared with $71 \%$ (34/ 48) for sodium cromoglycate and $59 \%$ (25/42) for placebo. There was no statistically significant difference between the groups. Clinician opinion also favoured nedocromil sodium, recording full/ moderate control in respectively $82 \%, 66 \%$, and $59 \%$ of the patient groups (not statistically significant).

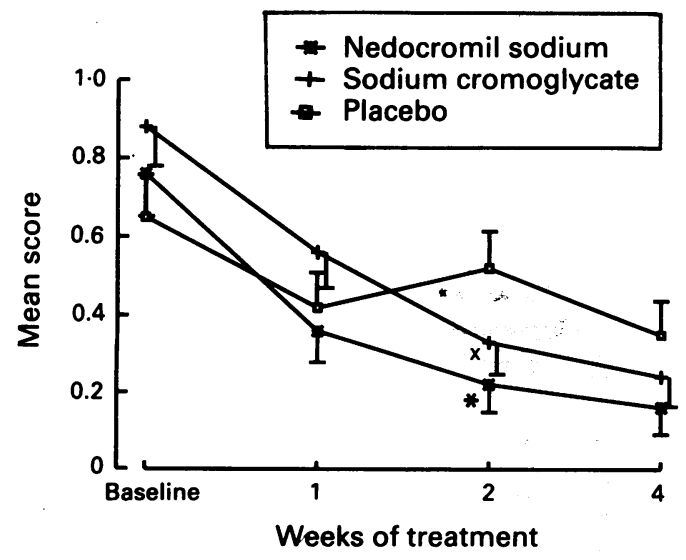

Figure 3 Clinical assessments of corneallimbal oedema. (Score: $4=$ very severe; 3 =severe; $2=$ moderate; $1=$ mild; $0=$ none.) Significance (pairwise comparison of changes from baseline $):{ }^{\star} p=0.012$ nedocromil sodium $\mathrm{v}$ placebo ${ }^{\times} p=0.015$ sodium cromoglycate $\mathrm{v}$ placebo.
All treatments were well accepted and no patients withdrew during the 4 week trial period. Ten patients reported unusual symptoms: five on nedocromil sodium, three on sodium cromoglycate, and two on placebo. Only three of these were considered to be probably related to the test treatment - namely, two instances of redness with sodium cromoglycate, and one of stinging with nedocromil sodium.

\section{Discussion}

This double masked, placebo controlled study compared the effectiveness of two mast cell stabilising, non-steroid, anti-inflammatory therapies in the management of VKC over a period of 4 weeks. In a chronic condition such as VKC, this is perhaps too short a time in which to expect striking clinical improvements over and above those due to the washing and lubricating effect of the placebo eye drops. However, the inclusion of a positive control group treated with 2\% ophthalmic sodium cromoglycate, a long established therapy for VKC, ${ }^{17}$ gave more weight to the trial design, allowing for a more realistic interpretation of the results.

Placebo effects frequently complicate clinical trials in patients with allergic conjunctivitis ${ }^{15} 18$ and this study was no exception to the rule, since a considerable symptomatic improvement occurred over 4 weeks of placebo treatment. At the same time, however, weekly mean diary card scores and clinical assessments showed a consistently greater reduction in disease severity with both of the active treatments. The beneficial effect of nedocromil sodium appeared greatest overall, and was more often statistically significant compared with placebo (Figs 1-3). This improvement in symptoms also occurred more rapidly with both the active therapies, and statistically significant advantages over placebo were seen in diary card severity scores during the first 2 weeks of active treatments (Table 1 ).

The more intractable signs of the disease, assessed at the clinic after 1,2 , and 4 weeks of treatment, were less likely to be improved by the placebo effect alone. The therapeutic response was thus more clearly demonstrated, and was 
particularly marked where baseline severity scores were in the region of 2 (=moderate), as for conjunctival chemosis. By the end of the study, in line with the general trend throughout, nedocromil sodium was found to be the most effective treatment and was significantly better than placebo in reducing chemosis of the bulbar and lower tarsal conjunctiva, bulbar papillae, and Trantas' dots and nodules. Sodium cromoglycate was intermediate for most criteria, and although better than placebo for bulbar papillae, Trantas' dots, and nodules, after 4 weeks was significantly $(p<0.05)$ less effective than nedocromil sodium in relieving bulbar and lower tarsal chemosis (Fig 2; Table 2).

These results showing increased efficacy of nedocromil sodium compared with sodium cromoglycate in VKC are in agreement with studies carried out in patients with seasonal allergic conjunctivitis (SAC) ${ }^{19}$ and rhinitis. ${ }^{20}$ The pharmacological profile of nedocromil sodium shows it to be more potent than sodium cromoglycate in inhibiting the activation of inflammatory cells ${ }^{21}$ and the results of clinical trials suggest that this increased potency translates into a greater therapeutic effect against allergic inflammatory diseases. That is, at least in VKC, nedocromil sodium seems to have the potential for a higher maximum of efficacy than sodium cromoglycate, rather than merely showing equivalent activity at a lower dose. Sodium cromoglycate appeared to be maximally effective in VKC at a dose of $2 \%$ four times daily since no further improvement was achieved by doubling the concentration, ${ }^{22}$ whereas in SAC the effect of sodium cromoglycate was clearly dose related. ${ }^{23}$ It is likely that the more chronic aspects of VKC, caused by the characteristic invasions of inflammatory cells including eosinophils and mucosal mast cells, can be more efficiently relieved by nedocromil sodium, which has been shown to reduce eosinophils, neutrophils, and lymphocytes in the tears of VKC patients. ${ }^{15}$ This localised anti-inflammatory activity of nedocromil sodium should reduce the need for corticosteroid treatment, providing a non-toxic alternative which appears to surpass the effectiveness of sodium cromoglycate. During this study, all the test treatments were well accepted by the patients and final opinions reflected the recorded data, showing a preferential trend for active therapy which favoured nedocromil sodium.

It is concluded that both $2 \%$ sodium cromoglycate and $2 \%$ nedocromil sodium ophthalmic solutions, applied four times daily over a 4 week period, were beneficial in controlling symptoms of VKC. Nedocromil sodium had a more pronounced effect than sodium cromoglycate, particularly apparent in the periodic clinical assessments. These results are compatible with the known anti-inflammatory and antiallergic properties of nedocromil sodium and suggest that this non-toxic, topical medication will have an important role in the management of VKC.

This study was supported by Fisons plc, Pharmaceutical Division, Loughborough, United Kingdom.

1 Ehlers WH, Donshik PC. Allergic ocular disorders: a spectrum of diseases. CLAOF 1992; 18: 117-24.

2 Abelson MB, George MA, Garofalo C. Differential diagnosis of ocular allergic disorders. Ann Allergy 1993; 70: 95-109.

3 Allansmith MR, Ross RN. Ocular allergy. Clin Allergy 1988; 18: 1-13.

4 Irani A-MA, Butrus SI, Tabbara KF, Schwartz LB. Human conjunctival mast cells: distribution of $\mathrm{MC}_{\mathrm{T}}$ and $\mathrm{MC}_{\mathrm{TC}}$ in vernal conjunctivitis and giant papillary conjunctivitis. f Allergy Clin Immunol 1990; 86: 34-40.

5 Romagnani S, Maggi E, Parronchi P, Macchia D, Piccinni MP, Ricci M. Increased numbers of Th2-like CD4+ T cells $\mathrm{MP}$, Ricci M. Increased numbers of Th2-like CD4+ T cells
in target organs and in the allergen-specific repertoire of in target organs and in the allergen-specific repertoire of
allergic patients. Possible role of $\mathrm{IL}-4$ produced by non-T allergic patients. Possible role of IL-4 produced by
cells. Int Arch Allergy Appl Immunol 1991; 94: 133-6.

6 Ciprandi G, Buscaglia S, Cerqueti PM, Canonica GW. Drug treatment of allergic conjunctivitis. A review of the evidence. Drugs 1992; 43: 154-76.

7 Urban RC, Cotlier E. Corticosteroid-induced cataracts. Surv Ophthalmol 1986; 31: 102-10.

8 Allansmith MR, Ross RN. Ocular allergy and mast cell stabilizers. Surv Ophthalmol 1986; 30: 229-44.

9 Kay AB, Walsh GM, Moqbel R, MacDonald AJ, Nagakura T, Carroll MP, et al. Disodium cromoglycate inhibits activation of human inflammatory cells in vitro. $\mathcal{F}$ Allergy Clin Immunol of human inflam 80 : 1-8.

10 El Hennawi $M$. Clinical trial with $2 \%$ sodium cromoglycate (Opticrom) in vernal keratoconjunctivitis. Br $\mathcal{F}$ Ophthalmol $1980 ; 64: 483-6$

11 Sorkin EM, Ward A. Ocular sodium cromoglycate. An overview of its therapeutic efficacy in allergic eye disease. Drugs 1986; 31: 131-48.

12 Knottnerus IG, Scott CN, Riley PA. Nedocromil sodium 2\% ophthalmic solution (Tilavist): a new topical treatment for ocular allergic inflammation. Ocular Immunol Inflamm 1993; 1: $27-30$.

13 Moqbel R, Cromwell O, Walsh GM, Wardlaw AJ, Kurlak L, Kay AB. Effects of nedocromil sodium (Tilade) on the activation of human eosinophils and neutrophils and activation of human eosinophils and neutrophils and the release

14 Orr TSC, Jackson DM, Greenwood B, Wells E, Eady RP. Nedocromil sodium: a selective mucosal mast cell stabilizer. In: Kay AB, ed. Asthma: clinical pharmacology and therapeutic progress. Oxford: Blackwell, 1986: 265-73.

15 Bonini ST, Barney NP, Schiavone M, Centofanti M, Berruto A, Bonini SE, et al. Effectiveness of nedocromil sodium $2 \%$ eye drops on clinical symptoms and tear fluid cytology of patients with vernal conjunctivitis. Eye 1992; 6: 648-52.

16 Bonini ST, Bonini SE. Vernal keratoconjunctivitis (VKC): pathophysiological and therapeutic studies. Ocular Immunol Inflamm 1993; 1: 13-7.

17 Collum LMT. The management of ocular allergy. Ocular Immunol Inflamm 1993; 1: 5-8.

18 BenEzra D. Round table discussion and questions. Ocular Immunol Inflamm 1993; 1: 35-40.

19 Leino M, Ennevaara K, Latvala A-L, Nordgren P, Posti A-M, Suves $\mathrm{R}$, et al. Double-blind group comparative study of $2 \%$ nedocromil sodium eye drops with $2 \%$ sodium cromoglycate and placebo eye drops in the treatment of seasonal allergic conjunctivitis. Clin Exp Allergy 1992; 22: 929-32.

20 Schuller DE, Selcow JE, Joos TH, Hannaway PJ, Hirsch SR, Schwartz HJ, et al. A multicenter trial of nedocromil sodium, $1 \%$ nasal solution, compared with cromolyn sodium and placebo in ragweed seasonal allergic rhinitis. $\mathcal{F}$ Allergy Clin Immunol 1990; 86: 554-61.

21 Brogden RN, Sorkin EM. Nedocromil sodium. An updated review of its pharmacological properties and therapeutic efficacy in asthma. Drugs 1993; 45: 693-715.

22 El Hennawi M. A comparison between $2 \%$ and $4 \%$ sodium cromoglycate eye drops in the treatment of vernal keratoconjunctivitis. Curr Eye Res 1983; 2: 765-8.

23 Vakil DV, Ayiomamitis A, Nizami RM. Treatment of seasonal conjunctivitis: comparison of $2 \%$ and $4 \%$ sodium cromoglycate ophthalmic solutions. Can $\mathcal{F}$ Ophthalmol 1984; 19: 207-11. 